\title{
ESTUDO DAS CARACTERÍSTICAS FISICO-QUÍMICAS DA ÁGUA DE LAVAGEM DE FILTRO EM UMA ESTAÇÃO DE TRATAMENTO DE ÁGUA PARA FINS DE REAPROVEITAMENTO
}

\author{
Cristiane Aparecida de Oliveira ${ }^{1}$ \\ Wellington França Barcelo ${ }^{2}$ \\ Carla Jovania Gomes Colares ${ }^{3}$
}

RESUMO: O crescimento populacional, industrial e econômico ocasionou o aumento do consumo de água potável no planeta. Observando-se a necessidade de reuso deste bem, o presente trabalho teve como objetivo avaliar a qualidade da água utilizada no processo de lavagem dos filtros da Estação de Tratamento de Água do tipo convencional de fluxo completo (ETA) da cidade de Anápolis/GO, com fins de reutilizá-la no processo inicial de tratamento da presente ETA. O estudo foi realizado nos meses de março a junho/2012 e agosto de 2012, onde se avaliou parâmetros físico-químicos e microbiológicos da água de lavagem dos filtros, totalizando cinco coletas. Os resultados médios obtidos foram: $2,41 \mathrm{mg} \mathrm{L}^{-1}$ para o alumínio, $2,49 \mathrm{mg} \mathrm{L}^{-1}$ para o ferro, $0,02 \mathrm{mg} \mathrm{L}^{-1}$ para o manganês, 7,80 para o pH, 140,8 UNT para a turbidez, 1,7.104 NMP $100 \mathrm{~mL}^{-1}$ para coliformes totais e 5,2.10 $\mathrm{NMP} 100 \mathrm{~mL}^{-1}$ para coliformes termotolerantes. Após os estudos das características da água de lavagem de filtro, foi possível averiguar que o retorno da mesma ao início do processo do tratamento pode ser realizado de forma controlada, pois os parâmetros alumínio, ferro, turbidez e coliformes encontram-se fora dos limites estabelecidos pelas Resoluções CONAMA 357/2005 e 430/2011 para águas doce de classe 2 e padrão de lançamento de efluentes. Sendo assim, faz-se necessário um estudo para otimização do processo de reutilização da água de lavagem dos filtros, que garantam que as características físico-químicas e microbiológicas estejam dentro dos padrões estabelecidos por estas resoluções.

Palavras chave: Efluente. Reuso. Otimização.

${ }^{3}$ Mestra em Recursos Hídricos e Saneamento Ambiental. E-mail: carlacolares1@gmail.com 


\section{1-INTRODUÇÃO}

As Estações de Tratamento de Água (ETA), unidades industriais de fundamental importância, tem por finalidade garantir a qualidade da água conforme os fins de utilização em que serão empregados. A forma com que será tratada a água e a tecnologia empregada varia conforme os fins a que se destina e as características da água bruta. $\mathrm{A}$ água tratada geralmente divide-se em duas formas de finalidades, uma com fins de potabilidade em sistemas públicos de abastecimento, e outro com aplicação industrial e comercial.

Observa-se que todo o esquema da ETA no Brasil assemelha-se com um processo industrial, portanto também geram resíduos. Os resíduos oriundos da ETA são descartados de acordo com a concepção do projeto da estação. No entanto, muitos projetos de estações de tratamento não preveem o destino desses resíduos e a maioria lança esses rejeitos em cursos d'água sem a preocupação com reuso, recuperação e impactos ambientais.

Assim, o presente estudo tem por objetivo caracterizar através de análises físicoquímicas a água de lavagem de filtros da estação de tratamento de água do tipo convencional de fluxo completo (ETA) da cidade de Anápolis - GO, a fim de se verificar a possibilidade de seu retorno ao processo inicial de produção uma vez que as mesmas são descartadas sem nenhum tipo de tratamento no Córrego dos Cesários.

\section{DESENVOLVIMENTO}

\subsection{Local de estudo: Estação de Tratamento de Água da cidade de Anápolis, Goiás}

A ETA escolhida para a realização desse estudo é a estação localizada no Jardim das Américas I Etapa, responsável pelo abastecimento da cidade e região. A referida ETA tem capacidade para tratar até 860 litros por segundo. Sua água é proveniente do sistema de captação que funciona no Ribeirão de Piancó, município de Abadiânia. (Figuras 1 e 2). 


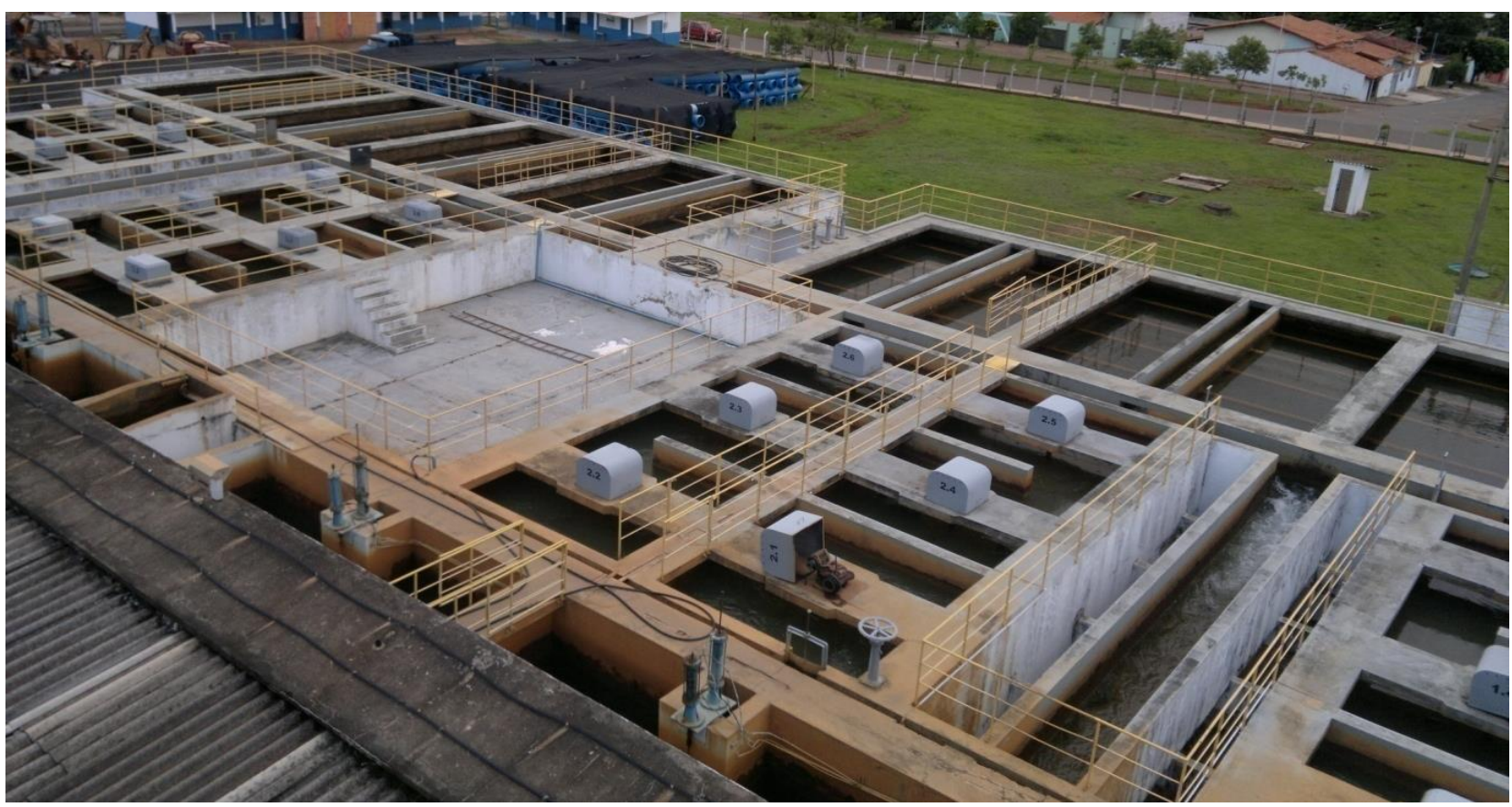

Figura 1 - Estação de Tratamento de Água no bairro Jardim das Américas I Etapa Anápolis/GO.

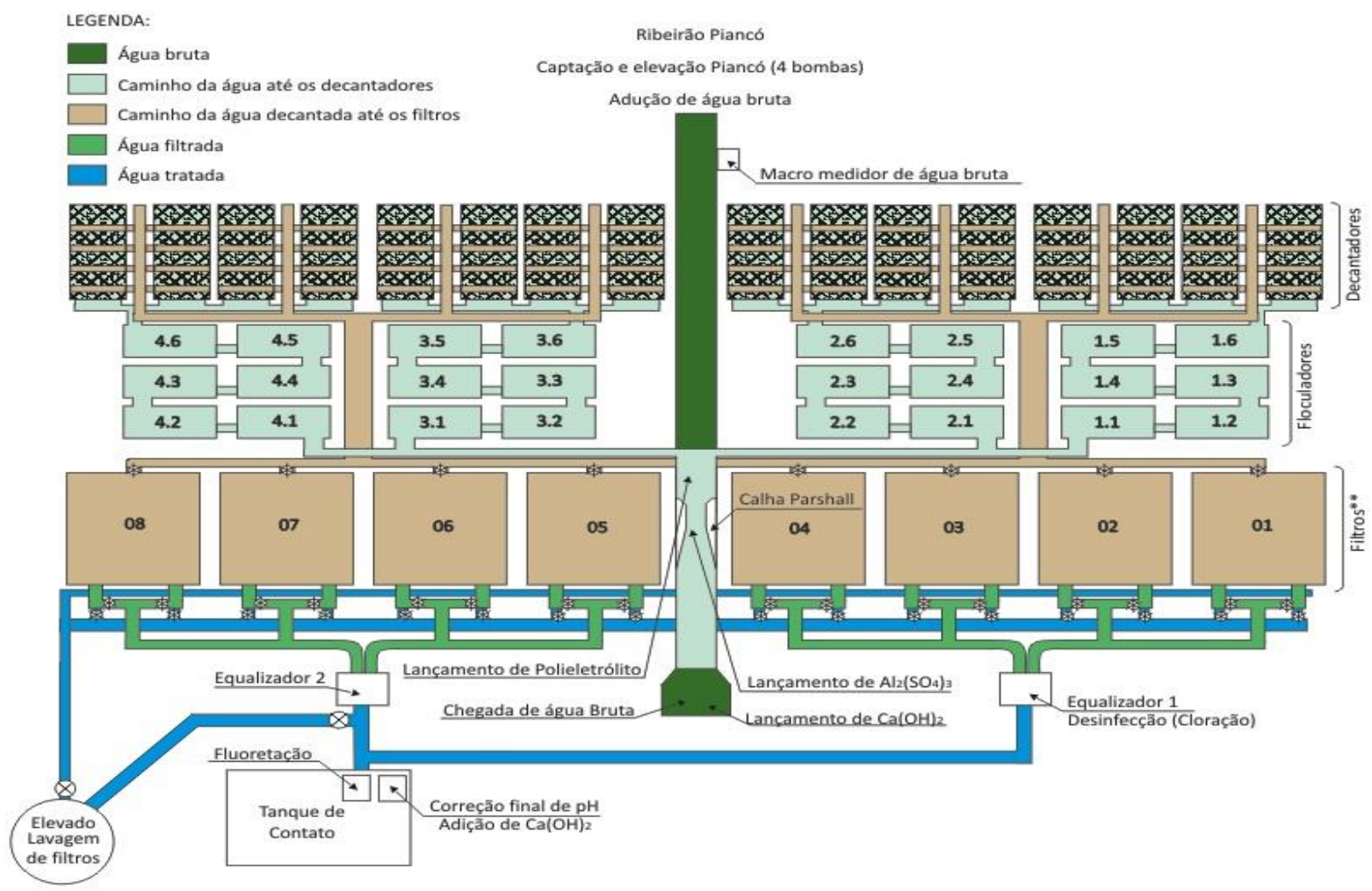

Figura 2 - Fluxograma das etapas do processo convencional do tratamento de água da ETA Anápolis/GO. Fonte: GÓIS (2012) 
Estações que utilizam o tipo de tratamento convencional realizam a remoção de partículas finas em suspensão e em solução presentes na água bruta. Na ETA Anápolis/GO, o processo se inicia com a chegada da água bruta captada por quatro bombas e conduzidas por meio de adutoras à estação de tratamento (Figuras 3 e 4).

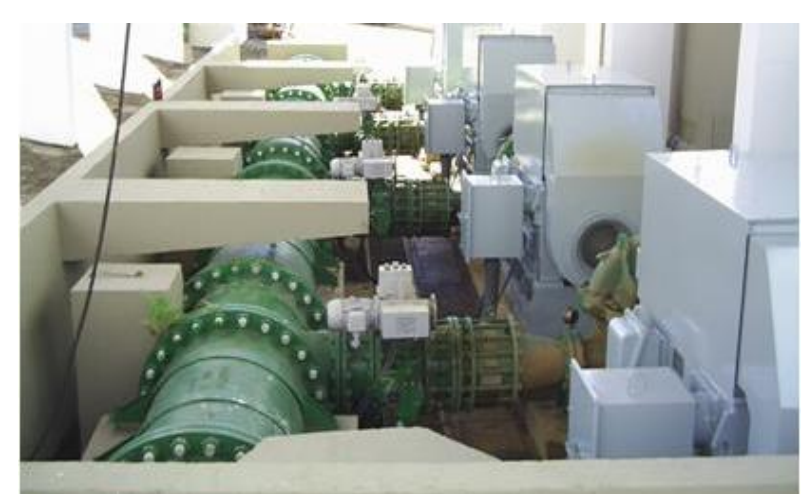

Figura 3 - Captação de água bruta - Ribeirão Piancó.

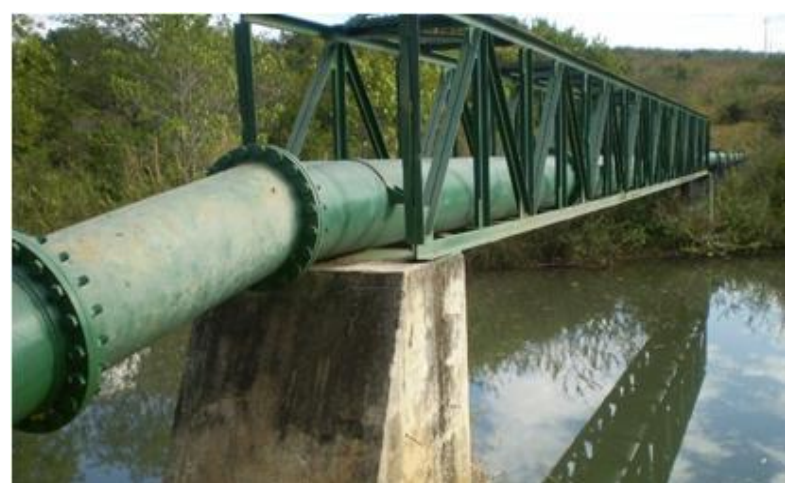

Figura 4 - Adução da água captada - Ribeirão Piancó.

A água bruta entra em uma câmara de dimensões 3,9 m de comprimento, 1,9 m de largura e 3,0 $\mathrm{m}$ de profundidade, onde é adicionada cal hidratada a uma vazão média mínima de $400 \mathrm{~kg} \mathrm{dia}^{-1}$ e uma vazão máxima de $800 \mathrm{~kg} \mathrm{dia}^{-1}$ empregada na alcalinização e elevação do pH da água bruta (Figura 5).

A coagulação da água bruta se dá com a adição de sulfato de alumínio hidratado aplicado na Calha Parshall (Figura 6). Esse componente químico desestabiliza as partículas coloidais de modo a ocorrer a formação de precipitado do coagulante com as impurezas (flocos) que são removidos posteriormente. Em seguida, a água coagulada é submetida à agitação para a formação de flocos e adquirirem a massa específica para se decantarem. Essa etapa é feita nos floculadores. A ETA em questão trabalha com quatro floculadores, sendo cada um, composto de seis câmaras, com seis impulsores rotativos. 


\section{S Fom Fórum Ambiental}

da Alta Paulista

ISSN 1980-0827

Volume 9, Número 11, 2013

Saúde, Saneamento e

Meio Ambiente

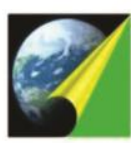

ANAP
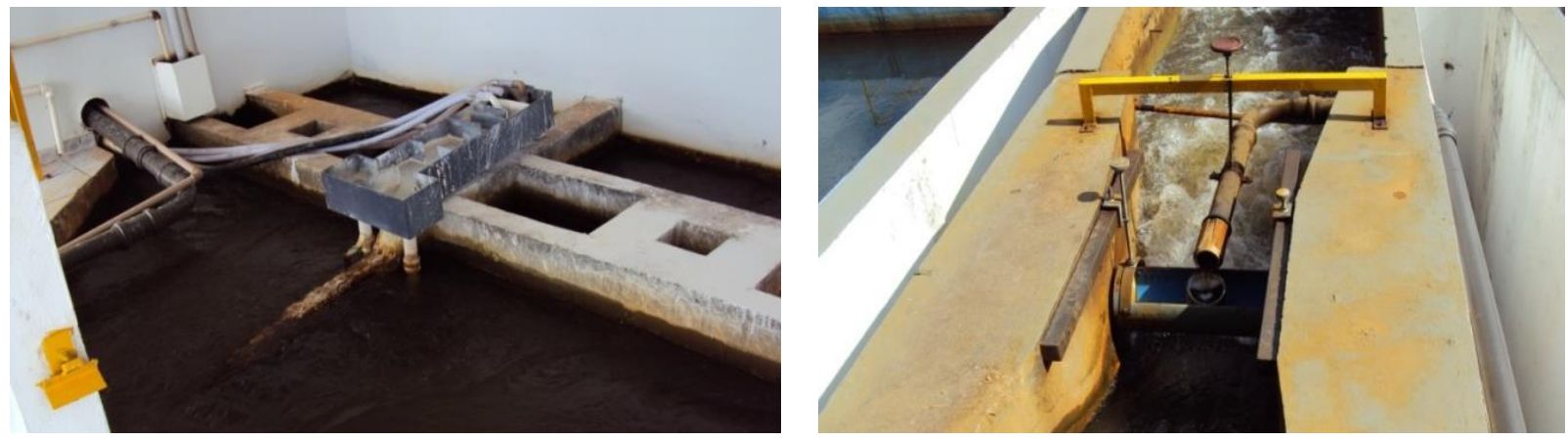

Figura 5 - Chegada da água bruta e dosagem da cal Figura 6 - Aplicação de $\mathrm{Al}_{2}\left(\mathrm{SO}_{4}\right)_{3}$ para correção do $\mathrm{pH}$.

Após a decantação, a água clarificada é filtrada por gravidade em oito filtros rápidos com dupla camada, uma de antracito e outra de areia. Após a saturação de impurezas no leito filtrante, é realizada uma lavagem superficial, seguida de uma retro lavagem, onde são consumidos, em média, $150 \mathrm{~m}^{3}$ de água potável por lavagem de filtro.

\subsection{Etapa de lavagem dos filtros}

A etapa de lavagem de filtros é de grande importância para se obter água de boa qualidade e imprescindível para que esta atinja os padrões de potabilidade recomendável ao consumo humano. Por meio dela são retiradas diversas partículas sólidas e sujeiras trazidas pelas tubulações em todo o processo de transporte da água bruta.

$\mathrm{Na}$ lavagem dos filtros a entrada da água deve ser maior que a saída a fim de possibilitar um acúmulo de água no filtro. Ela ocorre de modo ascendente conforme ilustrado na Figura 7 (a), (b) e (c), a areia, leito filtrante, é colocado em suspensão na água, sendo que a velocidade de ascensão da água deve ser suficiente para expandir esta areia. Usam-se grandes quantidades de água, que são descartadas.
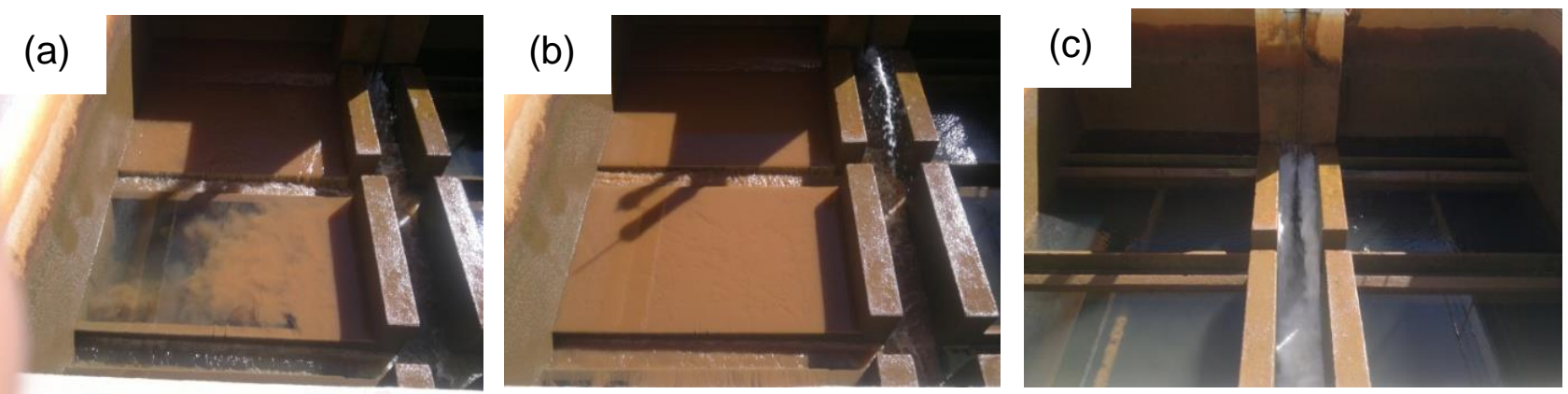

Figura 7 - (a) início da lavagem do filtro, (b) evolução do processo de lavagem e (c) etapa final da lavagem de Filtros da ETA Anápolis. 


\subsection{Características da Água de lavagem de Filtro em diferentes Estações de Tratamento no Brasil}

Silva et. al (2008) ao estudar a caracterização qualitativa, quantitativa e avaliação da possibilidade de reuso da água de lavagem dos filtros da ETA São Sebastião, Cuiabá - MT, analisou diversos parâmetros. Sua pesquisa demonstrou que em períodos de seca a qualidade da água bruta se assemelha à da água de lavagem de filtros, constando assim uma ineficiência nos decantadores da referida ETA justificada pela pouca quantidade de coagulante utilizada e formação de flocos mais leves exigindo uma limpeza maior dos filtros (SILVA et. al, 2008). No período de transição entre a estiagem e a época chuvosa acontece um ligeiro aumento na composição da água bruta e consequentemente da água de lavagem de filtro. Já no período chuvoso a taxa de elevação da turbidez da água bruta e da água de lavagem de filtros se mostraram acentuadas. Para a água de lavagem de filtros esse valor é ainda maior.

Em outro estudo realizado na ETA São Carlos, a água proveniente da lavagem de filtro equivale a $1,5 \%$ do volume da água tratada segundo relata Scalize (2000). Nesse estudo a turbidez média das amostras coletadas é de 147 UNT enquanto que o pH se encontra estável em 6,9 nas três amostras realizadas. Também se realizou a quantificação do alumínio que oscilou entre 2,60 a $4,40 \mathrm{mg} \mathrm{L}^{-1}$ chegando à média de 3,6 $\mathrm{mg} \mathrm{L}^{-1}, \mathrm{o}$ ferro $18,62 \mathrm{mg} \mathrm{L}^{-1}$ e o manganês $0,24 \mathrm{mg} \mathrm{L}^{-1}$.

A Tabela 1 apresenta as características da água de lavagem de filtro das duas ETA citadas, da ETA Anápolis/GO, e, ambas comparadas com os parâmetros de águas doces de classe 2 e lançamento de efluentes, estabelecidos pelas Resoluções CONAMA 357/2005 e 430/2011, respectivamente.

Tabela 1 - Características da água de lavagem de filtro de diferentes ETA do Brasil em comparação com a Resolução CONAMA 357/2005 para águas doce de classe 2 e CONAMA 430/2011 para padrão de lançamento de efluentes. 


\begin{tabular}{|c|c|c|c|c|c|c|}
\hline Parâmetros & Unidade & $\begin{array}{c}\text { CONAMA } \\
357 / 2005- \\
\text { classe } 2\end{array}$ & $\begin{array}{c}\text { CONAMA } \\
\text { 430/2011 - } \\
\text { padrão de } \\
\text { lançamento de } \\
\text { efluentes } \\
\end{array}$ & $\begin{array}{c}\text { ETA São } \\
\text { Sebastião/MT }\end{array}$ & $\begin{array}{c}\text { ETA São } \\
\text { Carlos /SP }\end{array}$ & $\begin{array}{c}\text { ETA } \\
\text { Anápolis/GO }\end{array}$ \\
\hline $\mathrm{pH}$ & - & $6,0-9,0$ & $5,0-9,0$ & 6,90 & 6,90 & 7,80 \\
\hline Turbidez & UNT & 40,00 & 100,00 & 151,40 & 147,00 & 140,80 \\
\hline Alumínio & $\mathrm{mg} \mathrm{L}^{-1}$ & 0,10 & - & - & 3,60 & 2,41 \\
\hline $\begin{array}{l}\text { Ferro } \\
\text { Solúvel }\end{array}$ & $\mathrm{mg} \mathrm{L}^{-1}$ & 0,30 & 15,00 & - & 18,62 & 2,49 \\
\hline $\begin{array}{l}\text { Manganês } \\
\text { Solúvel }\end{array}$ & $\mathrm{mg} \mathrm{L}^{-1}$ & 0,10 & 1,00 & - & 0,24 & 0,02 \\
\hline
\end{tabular}

(-) Não determinado

Pode-se notar que em ambas as ETA consideradas, os parâmetros analisados se encontram em nível semelhante e que, com exceção da turbidez e do ferro da ETA São Carlos/SP, turbidez da ETA São Sebastião/MT e da ETA Anápolis, os demais parâmetros se encontram adequados para serem lançados em corpos receptores, no entanto, se não forem tratados os parâmetros que estão acima do estabelecido pela Legislação, podem causar sérios impactos físicos, químicos e biológicos ao meio ambiente.

De qualquer maneira, reaproveitando as águas de lavagem de filtro ou não, as mesmas devem ser submetidas ao tratamento antes de sua disposição final. Devido aos elevados custos associados, legislação restritiva, aumento de dosagens de produtos químicos para o tratamento de água, convêm-se buscar formas de atender a esses requisitos sem prejuízo à empresa ou a exploração do consumidor.

\subsection{Aspectos tecnológicos de reutilização da água de lavagem dos filtros}

O presente estudo visa o desenvolvimento de uma tecnologia a qual a água utilizada na lavagem de filtro da Estação de Tratamento de Anápolis/GO retorne ao seu processo inicial evitando assim o desperdício e o descarte inadequado da mesma. Informações obtidas na Saneamento de Goiás S/A (SANEAGO/GO, 2003) demonstram que, os resíduos gerados na respectiva ETA são lançados diretamente no córrego dos Cesários, sem nenhum tipo de tratamento.

Deve-se levar em consideração que, ao propor o retorno das águas de lavagem dos filtros ao seu processo inicial é importante considerar o fato de estar adicionando ao ponto de retorno não apenas água, mas um grande conteúdo de sólidos filtrados. Se não 
verificado com cautela esta situação, pode-se alterar os parâmetros de tratamento e mesmo os procedimentos de filtração já estabelecidos pela ETA.

De acordo com Martins et. al. (2009) "Alguns autores ponderam, no entanto, que o retorno das águas de lavagem de filtros pode resultar em um benefício indireto, já que há presença de coagulante residual, facilita o processo de agregação".

\section{5 -Coletas e amostras}

Foram coletadas cinco amostras em cinco meses diferentes, ao longo do processo de lavagem dos filtros, em um intervalo de cinco minutos aproximadamente, após o lançamento concomitante do efluente de lavagem. A caracterização da água bruta foi utilizada para comparar os teores de impureza contidas na água antes do tratamento e os teores de impureza retidos nos resíduos gerados após a lavagem de filtros da ETA Anápolis/GO.

Os procedimentos de coleta, preservação, preparação e análise das amostras, seguiram o "Standard Methods for the Examination of Water and Wastewater (APHA, 2005)". A Figura 8 demonstra a coleta das amostras, realizada durante os três estágios na lavagem dos filtros a qual se pode ver com nitidez a turbidez da água.

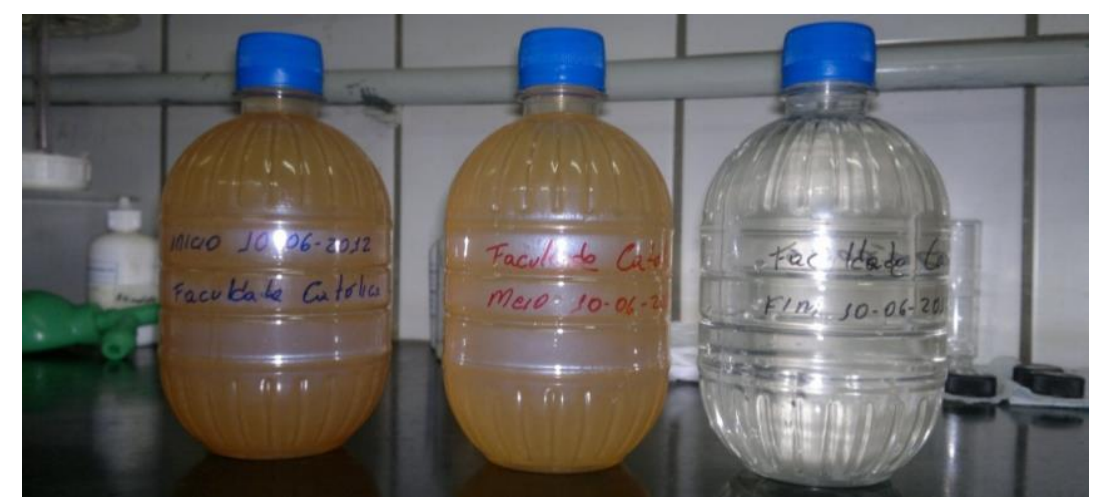

Figura 8 - Variação da turbidez da água de lavagem do filtro da ETA Anápolis/GO nas três fases da coleta.

\subsection{Caracterização da água bruta do Ribeirão Piancó- Córrego responsável pela água de abastecimento da cidade de Anápolis/GO}

A caracterização da água bruta do Ribeirão Piancó demonstra que a mesma atende aos padrões exigidos para classificação para águas doces de classe 2, conforme estabelecido pela resolução CONAMA no $357 / 2005$, os quais a maioria dos corpos 
hídricos do estado de Goiás pertence, não sendo registrados valores para os parâmetros alumínio, ferro e manganês (Tabela 2).

Tabela 2 - Caracterização físico-química e bacteriológica da água bruta do Ribeirão Piancó, no período de março a junho de 2012.

\begin{tabular}{|c|c|c|c|c|c|c|}
\hline \multirow[b]{2}{*}{$\begin{array}{l}\text { Natureza da } \\
\text { Análise }\end{array}$} & \multirow[b]{2}{*}{ Parâmetro } & \multirow[b]{2}{*}{ Unidade } & \multicolumn{4}{|c|}{ Data } \\
\hline & & & $\operatorname{mar} / 12$ & $a b r / 12$ & maio/12 & jun/12 \\
\hline \multirow{5}{*}{ Físico-Química } & Turbidez & UNT & 58,80 & 15,80 & 15,30 & 7,15 \\
\hline & & - & 6,22 & 6,39 & 6,33 & 6,38 \\
\hline & Alumínio & $\mathrm{mg} \mathrm{L}^{-1}$ & NR & $N R$ & NR & NR \\
\hline & Ferro & $\mathrm{mg} \mathrm{L}^{-1}$ & NR & NR & $N R$ & NR \\
\hline & Manganês & $\mathrm{mg} \mathrm{L}^{-1}$ & NR & NR & NR & NR \\
\hline \multirow[t]{2}{*}{ Bacteriológica } & $\begin{array}{l}\text { Coliformes } \\
\text { Totais }\end{array}$ & N.M.P. $100 \mathrm{~mL}^{-1}$ & $>1600$ & 1600 & 920 & 540 \\
\hline & $\begin{array}{l}\text { Coliformes } \\
\text { E.coli }\end{array}$ & N.M.P.100 mL- ${ }^{1}$ & NR & NR & NR & $N R$ \\
\hline
\end{tabular}

N.M.P. (Número Mais Provável): $100 \mathrm{~mL}^{-1}$ UNT: Unidade Nefolométrica de Turbidez NR: Não Registrado

\subsection{Análises de caracterização das amostras da água de lavagem dos filtros}

\subsubsection{Turbidez}

A turbidez da água de lavagem de filtro apresentou variações superiores aos limites preconizados pela Resolução CONAMA 357/2005 nas cinco amostras realizadas no presente estudo, conforme ilustra a Figura 9.

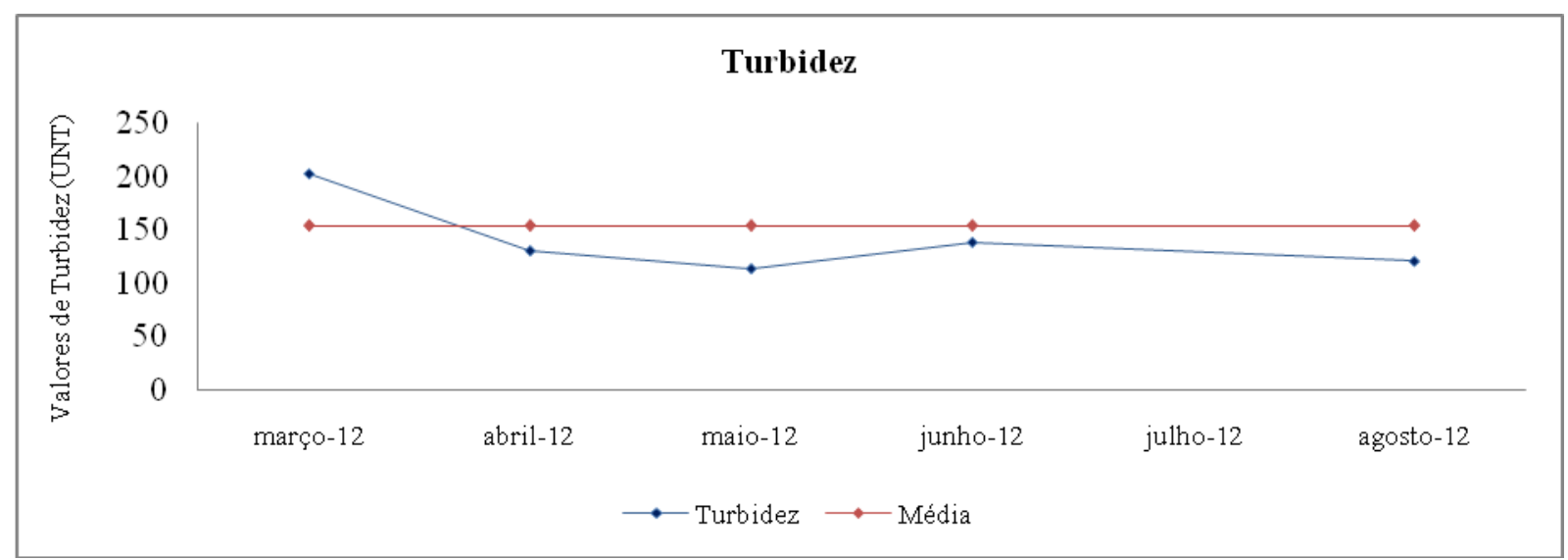

Figura 9 - Valores médios de turbidez obtidos nas análises da água de lavagem dos filtros da ETA/Anápolis. 
Esta resolução estabelece que para corpos hídricos de classe 2 deve-se ter valores máximos de 40 UNT. Nota-se que acontece uma tendência decrescente nos meses de março a maio voltando novamente a se elevar, mostrando que houve uma precipitação maior de chuva no mês de março e junho, indicando o possível aumento de partículas de natureza inorgânica, como siltes, argila e areia.

Camargo (2011) afirma que, em períodos chuvosos, as águas de lavagem de filtro devem ser monitoradas constantemente, pois uma turbidez elevada da água bruta ocasiona a saturação do filtro que, por conseguinte eleva o nível coluna de água sobre o leito filtrante.

\subsection{2 pH}

A variação de $\mathrm{pH}$ pode ser atribuída à adição do coagulante durante o processo de tratamento da água, conforme ilustra a Figura 10.

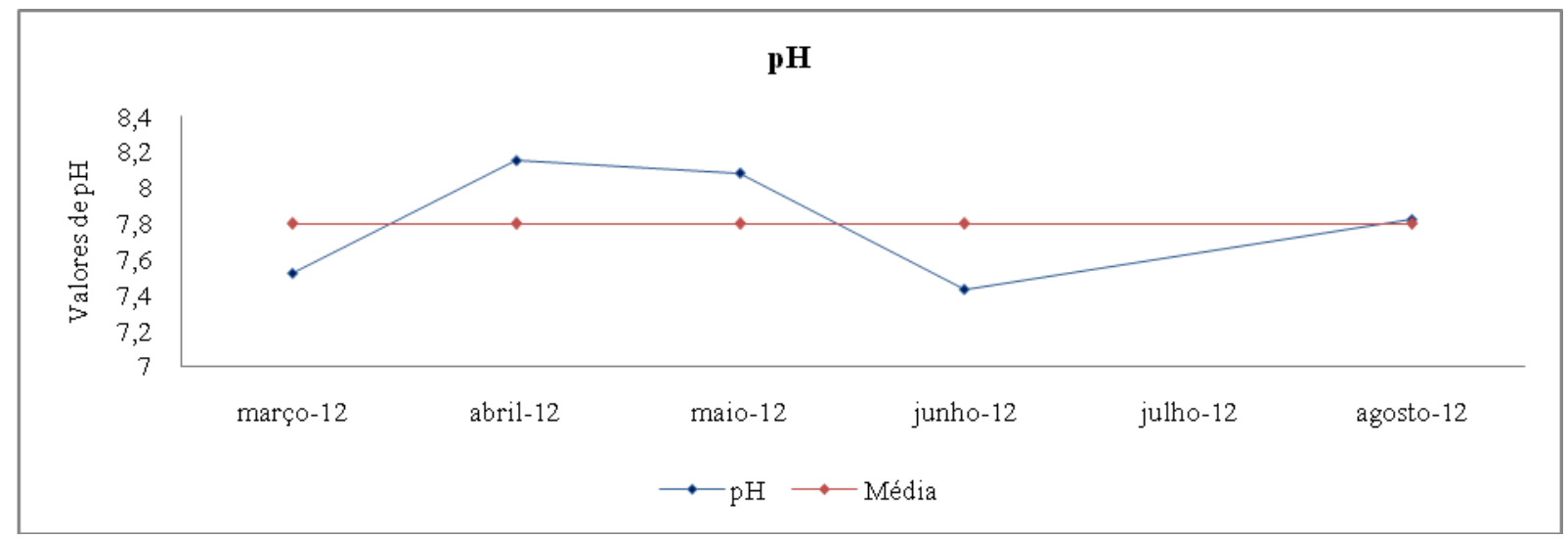

Figura 10 - Valores médios de pH obtidos nas análises da água de lavagem dos filtros da ETA Anápolis/GO.

Segundo Meneses (2005), o pH é, em geral, influenciado pelo teor de sulfato de alumínio na água, ou seja, maior concentração de sulfato de alumínio, menor valor do pH; sendo observado no presente estudo o decaimento destes valores nos meses considerados chuvosos.

As análises comprovaram que os valores de $\mathrm{pH}$ encontram-se dentro dos padrões exigidos pela resolução CONAMA 357/2005 a qual não deve ultrapassar os limites de 6,0 a 9,0 . 


\subsubsection{Alumínio}

Verificam-se altas concentrações de alumínio na água de lavagem dos filtros (ALF) nos meses de março e junho (Figura 11), podendo-se concluir que foram utilizadas elevadas quantidades do coagulante - sulfato de alumínio, a fim de se obter a qualidade da água para consumo, conforme estabelecidos pela Portaria 518/2005 do Ministério da Saúde.

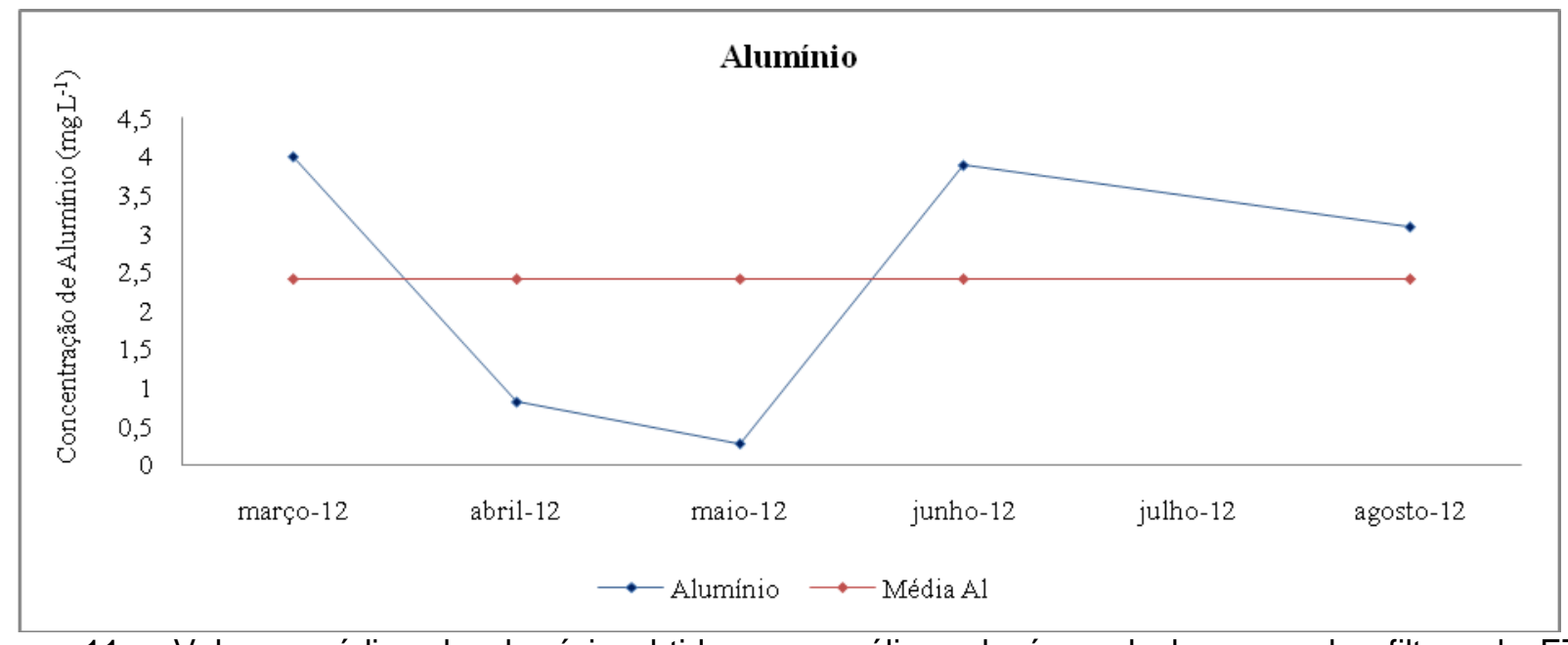

Figura 11 - Valores médios de alumínio obtidos nas análises da água de lavagem dos filtros da ETA Anápolis/GO.

A resolução CONAMA 357/2005 estabelece limite de $0,1 \mathrm{mg} \mathrm{L}^{-1}$ de alumínio corpos hídricos de classe 2, estando as concentrações apresentadas no presente estudo, acima deste valor.

De acordo com Menezes (2005), o alumínio na água é complexado e influenciado pelo $\mathrm{pH}$, temperatura e presença de fluoretos, sulfatos, matéria orgânica e outros ligantes. O aumento da concentração de alumínio está associado ao período de chuvas e, portanto, à alta turbidez. O acúmulo de alumínio no homem tem sido associado ao aumento de casos de demência senil do tipo Alzheimer (MENESES, 2005).

\subsubsection{Ferro}


Assim como o alumínio, foi observada a presença do elemento ferro em todas as análises realizadas no presente estudo, conforme demonstra a Figura 12.

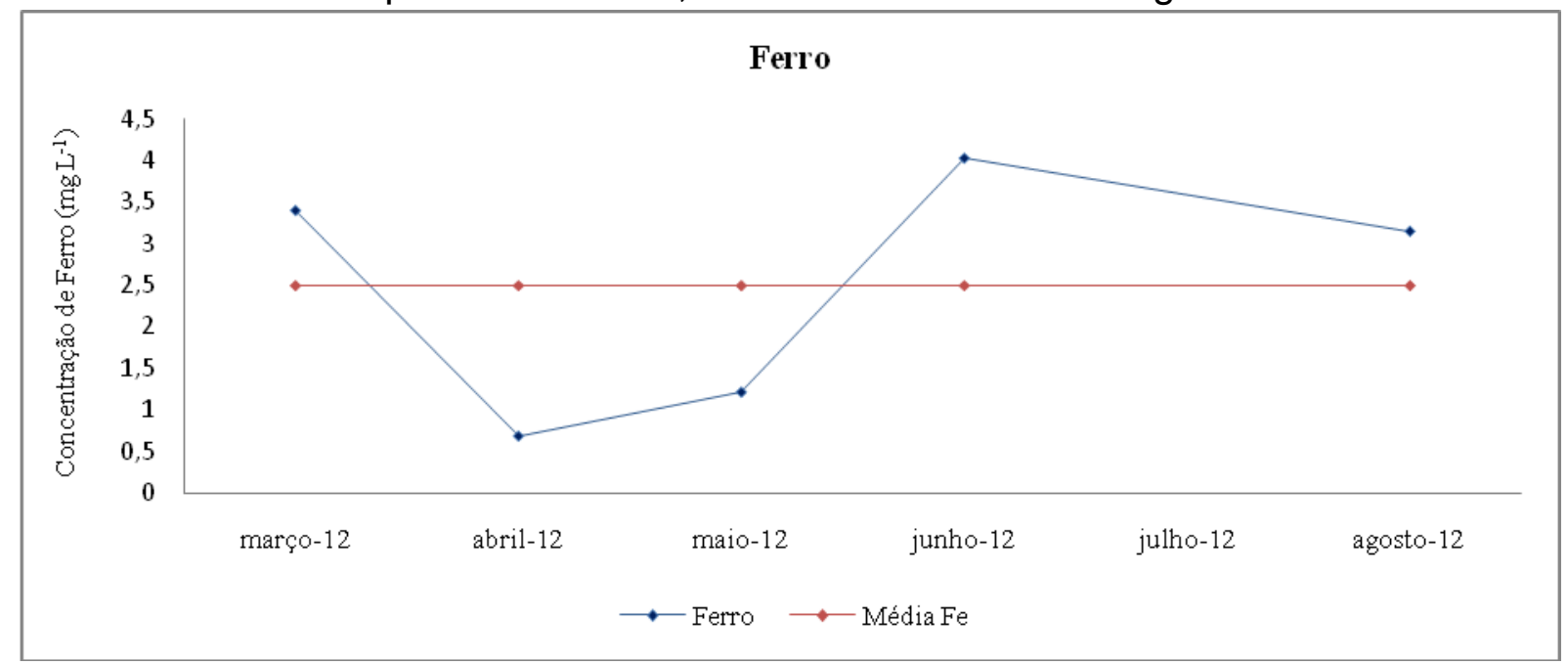

Figura 12 - Valores médios de ferro obtidos nas análises da água de lavagem dos filtros da ETA Anápolis/GO.

As concentrações de ferro obtidos nas análises realizadas encontram-se fora do limite de 0,3 $\mathrm{mg} \mathrm{L}^{-1}$ estabelecido pela resolução CONAMA 357/2005. O ferro, apesar de não se constituir um tóxico, traz diversos problemas para o abastecimento público de água, como por exemplo, confere cor e sabor à água, provocando mancha em roupas e utensílios sanitários; também traz o problema do desenvolvimento de depósitos em canalizações e de ferrobactérias, ocasionando a contaminação biológica da água, na própria rede de distribuição.

\subsubsection{Manganês}

Os valores de manganês encontrados na ALF (Figura 13) foram inferiores a 0,031 $\mathrm{mg} \mathrm{L}^{-1}$, estando abaixo do limite estabelecido pela Resolução CONAMA 357/2005, para lançamento de efluentes que é de $0,1 \mathrm{mg} \mathrm{L}^{-1}$. 


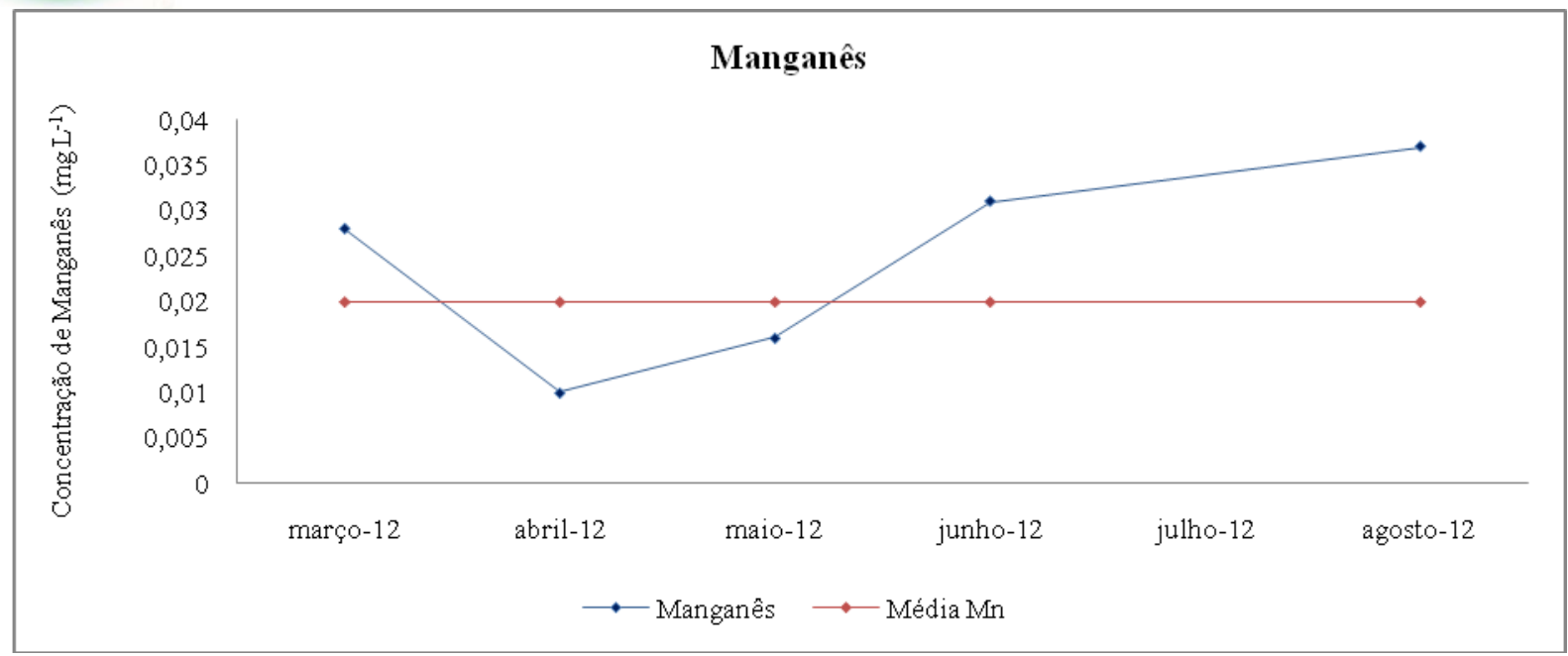

Figura 13 - Valores médios de manganês obtidos nas análises da água de lavagem dos filtros da ETA/Anápolis.

De acordo com Ferreira \& Laje Filho (1999), um dos principais motivos para restrição ao reuso da água da limpeza e lavagem das ETA é quando esta água apresenta uma qualidade microbiológica não satisfatória ou presença de ferro e manganês, o que se deve ao fato de que, sendo o processo de filtração uma operação de pré-concentração de sólidos e microrganismos, quando ocorre à reciclagem integral a água de lavagem pode prejudicar o processo de tratamento da fase líquida.

\subsubsection{Coliformes Totais}

A Figura 14 traz os valores de coliformes totais avaliados nas amostras de ALF.

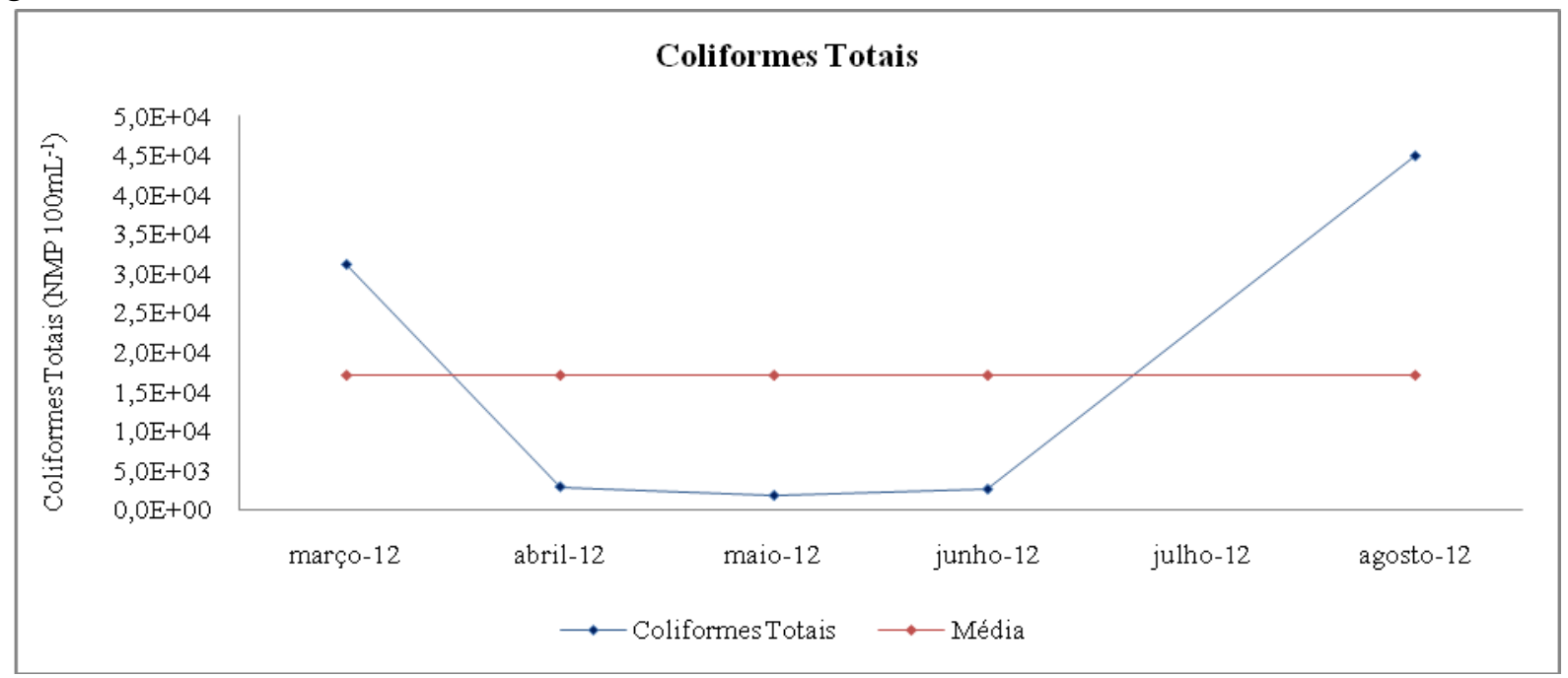

Figura 14 - Valores médios de Coliformes Totais obtidos nas análises da água de lavagem dos filtros da ETA Anápolis/GO. 
Verifica-se valores entre $5.10^{3}$ NMP $100 \mathrm{~mL}^{-1}$ a $5.10^{4} \mathrm{NMP} 100 \mathrm{~mL}^{-1}$ a para coliformes totais. A Resolução CONAMA 357/2005 determina que, para os demais usos das águas doces de classe 2, não deverá ser excedido um limite de 1.000 coliformes termotolerantes por 100 mililitros em $80 \%$ ou mais de pelo menos 6 (seis) amostras coletadas durante o período de um ano, com frequência bimestral. Portanto, todos os resultados encontrados neste estudo estão fora dos limites estabelecidos por esta resolução.

\subsubsection{Coliformes Termotolerantes}

Quanto aos valores de coliformes termotolerantes avaliados nas amostras de ALF, verifica-se um número muito elevado desses contaminantes biológicos (Figura 15).

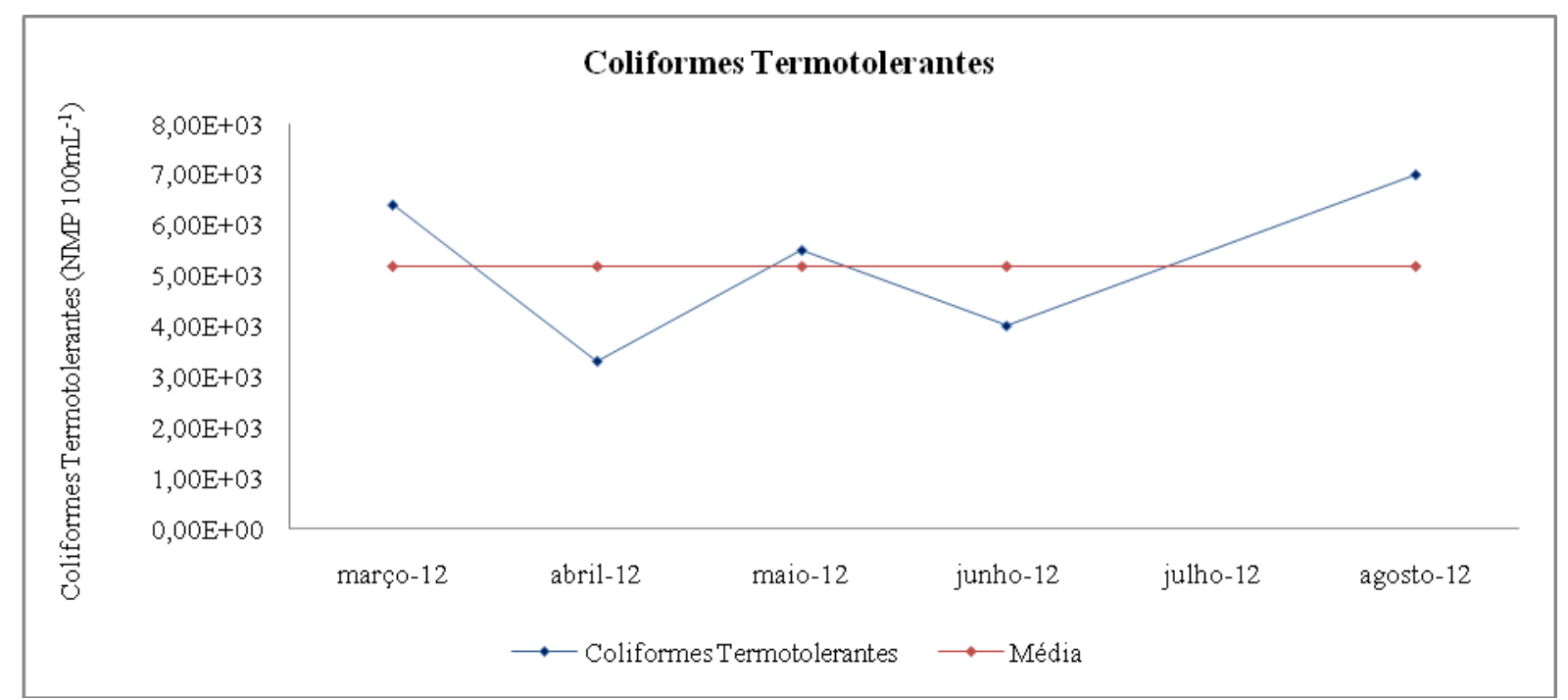

Figura 15 - Valores médios de coliformes termotolerantes obtidos nas análises da água de lavagem dos filtros da ETA Anápolis/GO.

Os coliformes termotolerantes são definidos como microrganismos do grupo coliforme representados principalmente pela Escherichia coli. Assim como na análise de coliformes totais, obteve-se para os coliformes termotolerantes valores superiores aos estabelecidos pela Resolução CONAMA 357/2005, ao estabelecer que a determinação de E. coli poderá ser determinada em substituição ao parâmetro coliformes termotolerantes de acordo com limites estabelecidos pelo órgão ambiental competente. Portanto os resultados encontrados que variaram entre $4.10^{3} \mathrm{NMP} 100 \mathrm{~mL}^{-1}$ a $7.10^{3}$. NMP $100 \mathrm{~mL}^{-1}$ também estão fora dos limites estabelecidos. 


\subsection{Proposta de implantação de reaproveitamento da ALF}

No estudo aqui descrito, a ideia principal é adotar o esquema de equalizadores para receber apenas a água da lavagem dos filtros que ocorre diariamente e onde são consumidos cerca de $1200 \mathrm{~m}^{3}$ de água tratada. Essas águas provenientes da lavagem dos filtros receberão o tratamento adequado objetivando o retorno ao início da produção. Esse procedimento diminuiria a necessidade no aumento da quantidade de bombeamento de água bruta.

Proposta semelhante e com resultados positivos foram avaliados na ETA Rio Descoberto/DF documentadas em uma tese de mestrado por Barbosa (1997) a qual ressalta que, "a avaliação dos resultados obtidos na recuperação da água de lavagem dos filtros da ETA-RD indica uma excelente tratabilidade da mesma, sem o comprometimento do desempenho da estação de tratamento de água".

No esquema proposto para a ETA Anápolis/GO, cada equalizador terá a capacidade para $150 \mathrm{~m}^{3}$ de efluente de lavagem de filtro onde se recolherá 0 sobrenadante a uma taxa de aproximadamente $43 \mathrm{Ls}^{-1}$. O recalque do efluente será feito por uma bomba de $10 \mathrm{CV}$ que efetivará a recirculação do mesmo para o começo do tratamento na ETA. O excedente retornará ao equalizador ocasionando assim o total esvaziamento do equalizador conforme Figura 16.

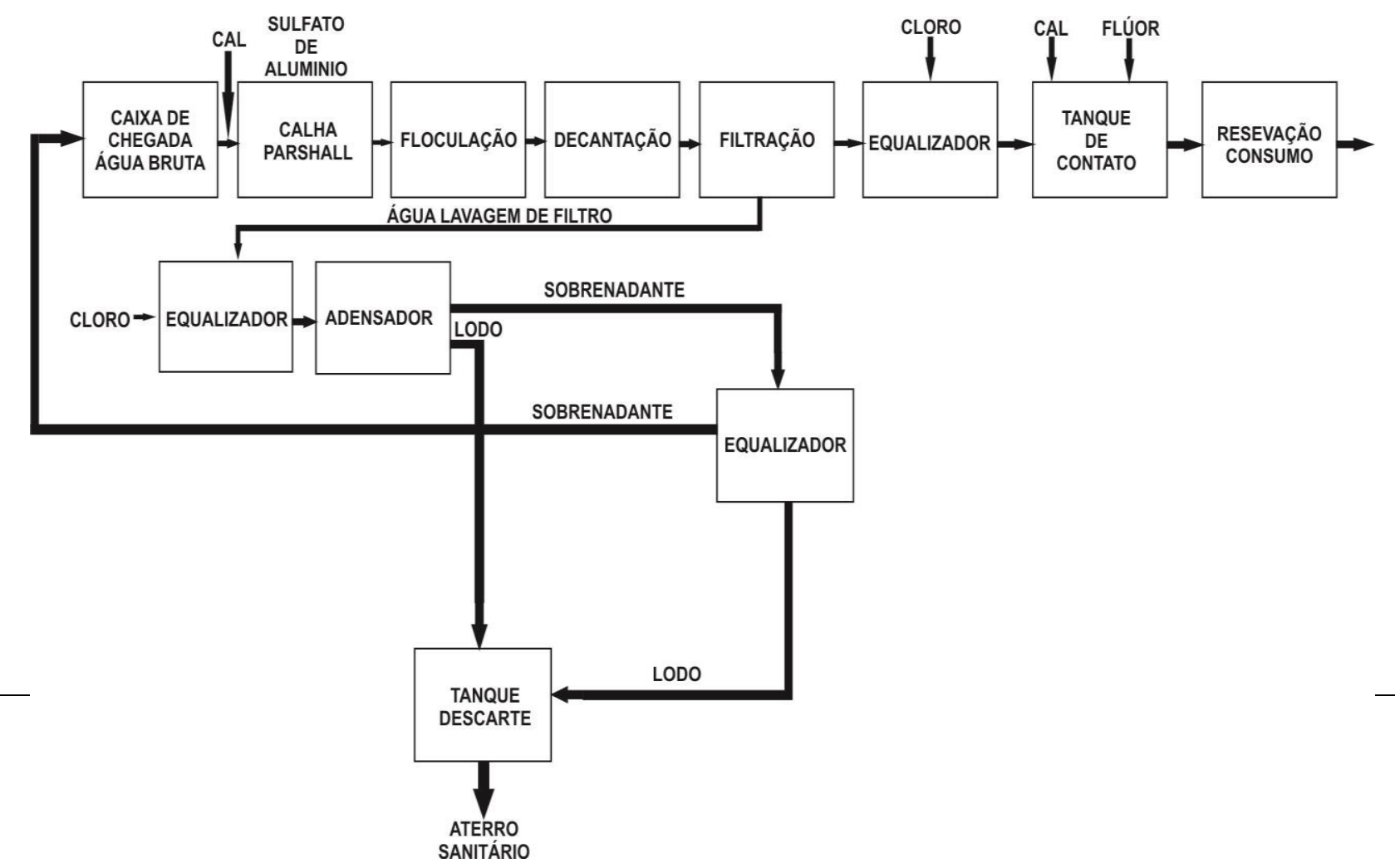


Figura 16 - Esquema da tecnologia proposta para a ETA Anápolis/GO.

Para verificar a qualidade da água presente nos equalizadores e adequá-la ao retorno do processo, deve se colher amostras após ser adicionado cloro, substância responsável pela eliminação dos microorganismos encontrados na água decantada do equalizador. O resultado das análises amostrais podem permitir a construção de uma curva de remoção de impurezas da unidade de filtração.

Para evitar a elevação da turbidez na água dos adensadores, se isso vier a ocorrer, propõe-se fazer o controle da concentração do lodo, para determinar o limite da concentração de sólidos e assim definir a frequência, os números de horas de operação e qual equipamento deverá entrar em operação. Os sólidos oriundos do adensador são conduzidos a um tanque de descarte de onde acontecerá o envio para o aterro sanitário.

\section{CONCLUSÃO}

A destinação inadequada das águas de lavagem de filtros e demais resíduos gerados nas Estações de Tratamento de Água são fatores preocupantes devido ao tipo de prática realizada por muitas ETA brasileiras. O reaproveitamento desses resíduos são objetos de estudo de diversos pesquisadores em inúmeras ETA do Brasil.

Analisando as características apresentadas pelos resíduos das coletas da água de lavagem de filtro realizadas durante o processo de experimentação na ETA Anápolis/GO, observou-se que o retorno da água de lavagem de filtro da ETA em estudo é viável desde que esta seja feita de maneira a estar em conformidade com os limites estabelecidos pelas Resoluções CONAMA 357/2005 e 430/2011.

O retorno da água de lavagem de filtro para a Estação de Tratamento de Água de Anápolis poderá levar ao aproveitamento equivalente a $1.200 \mathrm{~m}^{3}$ diários de água, volume este que deixarão de ser descartado em corpos hídricos, gerando assim benefícios econômicos e ambientais. 


\section{REFERÊNCIAS}

APHA; AWWA; WPCF. Standard methods for the examination of water and wastewater. 21a ed., Washington D.C., USA, American Public Health Association, 2005.

BRASIL, Ministério da Saúde. Portaria n 518, de 25 de março de 2004. Estabelece os procedimentos e responsabilidades relativos ao controle e vigilância da qualidade da água para consumo humano e seu padrão de potabilidade, e dá outras providências.- Série E. Legislação de Saúde. Brasília DF.

CAMARGO, R. P. L. et. al. Estudos de Resíduos gerados na ETA de Anápolis - GO: Caracterização e quantificação. (Dissertação de Mestrado). Universidade Estadual de Goiás - UEG, Unidade Universitária de Ciências Exatas e Tecnológicas, Anápolis - GO, 2011

CONAMA. Conselho Nacional do Meio Ambiente. Ministério do Meio Ambiente. Resolução n. 357 de 17 de março de 2005. Diário Oficial da União, Brasília, 2005. 23p. Estabelece normas e padrões para qualidade das águas, lançamentos de efluentes nos corpos receptores e dá outras providências.

CONAMA. Conselho Nacional do Meio Ambiente. Ministério do Meio Ambiente. Resolução n. 430 de 13 de maio de 2011. Diário Oficial da União, Brasília, 2011. 8p.

FERREIRA FILHO, S.S.; LAJE FILHO, F.A. Redução de perdas e tratamento de lodo em ETA. Programa Nacional de Combate ao Desperdício de Água - PNCDA. Brasília: SEPURB, 23p. 1999. Documentos Técnicos de Apoio.

GÓIS, P. F. Ensaios de tratabilidade de água bruta para instalação de filtração direta em estação de tratamento de água de Anápolis, Goiás. Anápolis. Dissertação (Mestrado). Mestrado em Engenharia Agrícola, Universidade Estadual de Goiás, 2012.

MARTINS, F. B. et.al. - XI ENGEMA: Encontro Nacional e I Encontro Internacional sobre Gestão Empresarial e Meio Ambiente - Reuso da Água de Retro-Lavagem de Filtros em Estações de Tratamento de Água: Estudo do Caso da ETA de Alvorada- RS, Fortaleza, - Universidade Luterana do Brasil - ULBRA, Canoas - RS, 2009. Disponível em:<http://www.unifor.br/docs/engema/apresentacao oral/ ENGEMA2009 242.pdf>. Acesso em: 14/07/2012.

MENESES, A.C.L.S.M. Presença de alumínio no efluente descartável gerado numa estação de tratamento de água e suas implicações na qualidade da água do corpo receptor. João Pessoa: PRODEMA/UFPB, Dissertação Mestrado, 2005. 110p.

SANEAGO - Manual de Operação de ETA. Instrução IT.07.0192 de 08 de setembro de 2003. 
SCALIZE, P. S.; DI BERNARDO, L. Caracterização da água de Lavagem de Filtros Rápidos de Estações de Tratamento de Água e dos Sobrenadantes e Sedimentos obtidos após ensaios de Clarificação utilizando Polímero Aniônico. Rio Grande do Sul, 2000. Disponível em: <http://www.bvsde.paho.org/bvsaidis/tratagua/ii-023.pdf>. Acesso em 26/07/2012.

SILVA, G.C.O. et. al. Caracterização Quali-Quantitativa e Avaliação da Possibilidade de Reuso da Água de Lavagem dos Filtros da ETA São Sebastião, Cuiabá - MT. Revista Águas Subterrâneas. XV Congresso Brasileiro de Água Subterrâneas, 2008. Disponível em: <http://aguassubterraneas.emnuvens.com.br/asubterraneas/article/view/23422/15508>. Acesso em 26/07/2012. 